\title{
Evaluation and validity of the Danish version of the Adult Strabismus Questionnaire AS-20
}

\author{
This article was published in the following Dove Press journal: \\ Clinical Ophthalmology \\ 31 December 2015 \\ Number of times this article has been viewed
}

\author{
Nafisa Ali ${ }^{1}$ \\ Mette S Sørensen² \\ Torben L Sørensen ${ }^{1,3}$ \\ Panteleimon Mortzos' \\ 'Department of Ophthalmology, \\ Copenhagen University Hospital \\ Roskilde, Roskilde, ${ }^{2}$ Research Unit \\ for Women's and Children's Health, \\ National University Hospital, ${ }^{3}$ Faculty \\ of Health Sciences, University of \\ Copenhagen, Copenhagen, Denmark
}

Purpose: Assessing health-related quality of life in patients with strabismus is important in evaluating the clinical benefits of strabismus treatment. The purpose of this study was to translate the Adult Strabismus Quality of Life Questionnaire (AS-20) into Danish and evaluate its reliability and validity in adult patients with strabismus in Denmark.

Methods: The AS-20 was translated into Danish in accordance with standard international adopted methods. We presented the questionnaire to 64 adults with strabismus and to 13 nonstrabismic adult controls. We tested the reliability of the Danish version by reassuring test-retest reliability, estimated the internal consistency, and analyzed the validity (discriminatory power) of the questionnaire by comparing patient scores with scores from control individuals.

Results: The Danish AS-20 produced high level of internal consistency (Cronbach's $\alpha$ values) for both subscales (psychosocial: 0.95 and functional: 0.85 ). We found good discriminatory power of the AS-20. The patients scored significantly lower not only on AS-20 composite score ( median $=63$, interquartile range $[\mathrm{IQR}]=44-79$ ) compared to healthy individuals ( median $=98$, IQR $=93-100)(P<0.0001)$ but also on all individual questions in both subscales (psychosocial: 1-10 and functional: 11-20).

Conclusion: The Danish version of AS-20 shows high reliability and validity, and in our opinion, AS-20 is therefore a suitable instrument for evaluating self-perceived psychosocial and functional influence of strabismus.

Keywords: AS-20, strabismus, questionnaire

\section{Introduction}

Strabismus refers to any misalignment of the eyes, and it is a common ophthalmologic disorder. Functionally, strabismus compromises depth perception, may cause asthenopia, and characterizes binocular diplopia. In addition, several studies have demonstrated the negative psychosocial impact strabismus has on quality of life (QOL), through health-related quality of life (HRQOL) assessment. ${ }^{1-7}$ In particular by impacting appearance, strabismus has negative effects on not only self-image and self-esteem but also social prejudice that may affect career opportunities.

The Adult Strabismus Quality of Life Questionnaire (AS-20) ${ }^{8}$ is an HRQOL instrument that, different from previously developed questionnaires, is patient derived. That is, the questions included in the AS-20 are chosen based on using in-depth focus group interviews with patients. AS-20 addresses specific issues affecting QOL and at the same time is widely applicable to the majority of adult patients irrespective of type of strabismus. Questions that may have discriminated between individuals with varying economic status (eg, driving) or cultural background have been excluded. The questionnaire generates 20 items with two subscales: ten items in a psychosocial subscale and ten items in a functional subscale. The first subscale covers primarily self-awareness, while the second scale covers physical and emotional functions. The composite score
Correspondence: Panteleimon Mortzos Department of Ophthalmology, Copenhagen University Hospital Roskilde, Køgevej 7-I3, 4000 Roskilde, Denmark $\mathrm{Tel}+454732390$ I

Email pmz@regionsjaelland.dk (c) (i) (5) 2016 Ali et al. This work is published by Dove Medical Press Limited, and licensed under Creative Commons Attribution - Non Commercial (unported, v3.0) License. The full terms of the License are available at http://creativecommons.org/licenses/lby-nc/3.0/. Non-commercial uses of the work are permitted without any further from Dove Medical Press Limited, provided the work is properly attributed. Permissions beyond the scope of the License are administered by Dove Medical Press Limited. Information on how to request permission may be found at: http://www.dovepress.com/permissions.php 
is derived from a mean value of all subscale scores and covers scores from 0 (worst self-perceived strabismus-related QOL) to 100 (best self-perceived strabismus-related QOL). Each subscale question consists of a 5-point Likert-type scale: never (score 100), rarely (score 75), sometimes (score 50), often (score 25), and always (score 0). Validation studies of the original English version of the AS-20 questionnaire have shown that the questionnaire is a valid tool for assessing self-perceived impact of strabismus on patients and is sensitive in measuring treatment outcomes following strabismus surgery..$^{9-11}$ A recent study showed that AS-20 translated into Chinese had satisfactory reliability and validity in Chinese patients with strabismus. ${ }^{12}$ The purpose of this study was to develop a Danish version of AS-20 questionnaire and test its reliability and validity.

\section{Materials and methods}

\section{Translation of the questionnaire}

The translation was done in conformity with internationally adopted standard methods. This includes forward translation, back translation, examination quality, and adjudication by bilingual speakers. The initial translation was then presented to ten patients with strabismus and it was noted if patients expressed confusion or the questions seemed ambiguous to the patient. Comments and suggestions were taken into account and the final translation was established.

\section{Study population}

The Department of Ophthalmology at the Copenhagen University Hospital, Roskilde, is a tertiary referral center for strabismus treatment and surgery in the Region of Zealand (population of $\sim 850,000$ ). We recruited patients older than 17 years of age, with obvious strabismus, referred from community ophthalmologists or other hospitals for treatment. Patients who could not read or understand Danish or were cognitively impaired were excluded from this study. We presented the questionnaire to 64 adult strabismus patients aged 17-81 years and 13 individuals with no known eye disease.

The questionnaire was presented to patients after the clinical examination. A blank space on the last sheet was available for any written comments. Assistance was offered if needed.

From the strabismic group, 12 patients were randomly selected (every fourth patient) to investigate test-retest reliability. Retesting took place 10-12 days later, either by telephone interview or in the clinic before surgery.

All participating individuals gave informed consent. According to Danish law, the use of questionnaires is not subject to review by the Regional Board of Ethics in Medical Research.

\section{Statistics}

Test for reliability was performed with Cronbach's $\alpha$ value as the index for internal consistency of each subscale. Test-retest reliability was quantified using the intraclass correlation and test-retest correlations. Test for validity was calculated using Pearson's rank correlations. Comparisons between patients and controls (discriminatory power) were performed using the Mann-Whitney test. A $P$-value of $<0.05$ was considered significant. All data were analyzed using SPSS software Version 21 for Windows.

\section{Results}

\section{Translation}

Small changes from the original version were made to ensure that the text gave a clear and similar meaning in Danish.

Specifically, item 5 "People don't give me opportunities because of my eyes" was back translated to "I feel by passed when it comes to opportunities, because of my eyes". Item 6 was back translated to "it makes me uncomfortable or nervous to know that people think about my squint".

All participants answered all the 5-level Likert questions of the questionnaire within a few minutes, and there were none who asked for assistance apart from three who expressed confusion about item 14 (problems with depth perception). A few patients added written comments on strabismus-related functional problems they specifically faced, which in their view were not included in the questionnaire. These were found to be expressing more specific problems, for example, trouble with "driving in the evening" or "pouring a glass of water from a jar".

Table 1 shows the baseline characteristics. For the 25 patients with esodeviation, the median angle of deviation measured with prism and alternating cover test (PACT) at a distance was 31 prism diopters (PD) (PD range 14-70). For the 30 patients with exodeviation, the median PACT at distance was 40 PD (PD range 16-85). For the ten patients with vertical deviation, the median PACT at distance was 20 PD (PD range 8-25). No PACT was performed on control adults.

A total of 18 patients out of 64 had best-corrected visual acuity worst than 20/30 in one eye because of strabismic (or mixed with anisometropic) amblyopia (16 eyes), previous retinal detachment (one eye), and age-related macular degeneration (one eye). The other 46 patients had best-corrected visual acuity 20/25 or better in both eyes (median 20/20 in each eye). 
Table I Summary of demographic and clinical data of all subjects

\begin{tabular}{lllll}
\hline Group & Age (years) & Sex (M/F) & Diagnosis & Diplopia (N) \\
\hline Strabismus & N=64 & $17 / 40$ & N of exotropia $=30$ & N of esotropia $=25$ \\
& Median $=46$ & & \\
Min-max $=|7-8|$ & & \\
Controls & $\mathrm{N}=13$ & $5 / 8$ & \\
& Median $=50$ & & \\
& Min-max $=30-74$ & & \\
\hline
\end{tabular}

Abbreviations: $M$, male; $F$, female; $N$, number.

\section{Reliability}

We found high level of internal consistency (Cronbach's $\alpha$ values) for both subscales (psychosocial: 0.95 and functional: 0.82 ). Inter-item correlations on both subscales were also high in the psychosocial scale (range 0.457-0.844), while in the functional scale, some low correlations were observed (range 0.04-0.658) in agreement with the lower Cronbach's $\alpha$ in that subscale, suggesting that functional questions are not as reliable as the psychosocial questions even though the functional scale does reach an acceptable Cronbach's reliability score (Table 2, Supplementary material).

\section{Validity}

We found good discriminatory power of the AS-20. The patients scored significantly lower not only on AS-20 composite score (median 63, interquartile range [IQR] 44-79) compared to healthy individuals (median 98, IQR 93-100) $(P<0.0001)$ but also on all individual questions in both subscales (psychosocial: 1-10 and functional: 11-20) (data not shown). There was no ceiling/floor effect among the patients (Table 3).

All the item-internal consistencies were $>0.5$, and all itemdiscrimination validities, except for item 14 , were $<0.50$.

Surprisingly, patients with diplopia did not have lower scores on the functional subscale than patients without diplopia (Table 4).

\section{Discussion}

The goal of this study was to test the reliability and validity of a Danish version of AS-20 questionnaire when presented to adult patients with strabismus. Overall, the psychometric results show that the Danish version of AS-20 is a stable,

Table 2 Inter-item correlation matrix

\begin{tabular}{|c|c|c|c|c|c|c|c|c|c|c|}
\hline \multicolumn{11}{|c|}{ Psychosocial scale (questions I-I0) } \\
\hline & QI & Q2 & Q3 & Q4 & Q5 & Q6 & Q7 & Q8 & Q9 & Q10 \\
\hline Q। & 1.000 & 0.806 & 0.844 & 0.859 & 0.572 & 0.798 & 0.640 & 0.774 & 0.622 & 0.706 \\
\hline Q2 & 0.806 & 1.000 & 0.744 & 0.811 & 0.457 & 0.666 & 0.628 & 0.675 & 0.677 & 0.601 \\
\hline Q3 & 0.844 & 0.744 & 1.000 & 0.861 & 0.463 & 0.784 & 0.568 & 0.744 & 0.574 & 0.666 \\
\hline Q4 & 0.859 & $0.8 \mathrm{II}$ & $0.86 I$ & 1.000 & 0.529 & 0.782 & 0.658 & 0.823 & 0.636 & 0.759 \\
\hline Q5 & 0.572 & 0.457 & 0.463 & 0.529 & 1.000 & 0.574 & 0.557 & 0.675 & 0.636 & 0.651 \\
\hline Q6 & 0.798 & 0.666 & 0.784 & 0.782 & 0.574 & 1.000 & 0.625 & 0.785 & 0.592 & 0.717 \\
\hline Q7 & 0.640 & 0.628 & 0.568 & 0.658 & 0.557 & 0.625 & 1.000 & 0.624 & 0.722 & 0.697 \\
\hline Q8 & 0.774 & 0.675 & 0.744 & 0.823 & 0.675 & 0.785 & 0.624 & 1.000 & 0.685 & 0.770 \\
\hline Q9 & 0.622 & 0.677 & 0.574 & 0.636 & 0.636 & 0.592 & 0.722 & 0.685 & 1.000 & 0.527 \\
\hline Q10 & 0.706 & 0.601 & 0.666 & 0.759 & 0.651 & 0.717 & 0.697 & 0.770 & 0.527 & 1.000 \\
\hline \multicolumn{11}{|c|}{ Functional scale (questions II-20) } \\
\hline QII & 1.000 & 0.341 & 0.479 & 0.179 & 0.479 & 0.344 & 0.215 & 0.446 & 0.443 & 0.041 \\
\hline Q12 & $0.34 I$ & 1.000 & 0.527 & 0.272 & 0.581 & 0.271 & 0.235 & 0.325 & 0.658 & 0.195 \\
\hline Q13 & 0.479 & 0.527 & 1.000 & 0.104 & 0.263 & 0.381 & 0.114 & 0.634 & 0.479 & 0.165 \\
\hline Q15 & 0.179 & 0.272 & 0.104 & 1.000 & 0.416 & 0.269 & 0.160 & 0.206 & 0.502 & 0.223 \\
\hline Q16 & 0.479 & $0.58 \mathrm{I}$ & 0.263 & 0.416 & 1.000 & 0.191 & 0.264 & 0.295 & 0.682 & 0.198 \\
\hline Q17 & 0.344 & 0.271 & 0.381 & 0.269 & 0.191 & 1.000 & 0.413 & 0.548 & 0.311 & 0.081 \\
\hline Q18 & 0.215 & 0.235 & 0.114 & 0.160 & 0.264 & 0.413 & 1.000 & 0.267 & 0.238 & 0.009 \\
\hline Q19 & 0.446 & 0.325 & 0.634 & 0.206 & 0.295 & 0.548 & 0.267 & 1.000 & 0.459 & 0.111 \\
\hline Q20 & 0.443 & 0.658 & 0.479 & 0.502 & 0.682 & 0.311 & 0.238 & 0.459 & 1.000 & 0.243 \\
\hline Q14 & 0.041 & 0.195 & 0.165 & 0.223 & 0.198 & 0.081 & 0.009 & 0.111 & 0.243 & 1.000 \\
\hline
\end{tabular}

Notes: Items I- 10 belong to the psychosocial subscale and items II-20 belong to the functional subscale. All 20 items had item-internal consistencies $>0.5$. All but item I4 had item discrimination $<0.50$. For item details, see Supplementary material. 
Table 3 Ceiling/floor effect in healthy patients and patients with strabismus

\begin{tabular}{llll}
\hline $\begin{array}{llll}\text { Question } \\
\text { number }\end{array}$ & \multicolumn{2}{l}{ Ceiling/floor $(\%)$} & $\begin{array}{l}\text { Test-retest } \\
\text { (P-value) }\end{array}$ \\
\cline { 2 - 3 } Q1 & Strabismus & Healthy & \\
Q2 & $14 / 19$ & $92 / 8$ & 0.56 \\
Q3 & $10 / 19$ & $100 / 0$ & 0.18 \\
Q4 & $16 / 17$ & $100 / 0$ & 0.70 \\
Q5 & $12 / 21$ & $100 / 0$ & 0.15 \\
Q6 & $43 / 9$ & $100 / 0$ & 0.15 \\
Q7 & $22 / 16$ & $100 / 0$ & 0.41 \\
Q8 & $26 / 3$ & $100 / 0$ & 0.18 \\
Q9 & $38 / 16$ & $100 / 0$ & 0.15 \\
Q10 & $29 / 3$ & $100 / 0$ & 0.31 \\
Q11 & $40 / 12$ & $100 / 0$ & 1.0 \\
Q12 & $21 / 5$ & $92 / 8$ & 0.10 \\
Q13 & $62 / 2$ & $92 / 8$ & 0.31 \\
Q14 & $45 / 2$ & $85 / 8$ & 0.48 \\
Q15 & $95 / 16$ & $92 / 8$ & 0.51 \\
Q16 & $3 / 3$ & $85 / 8$ & 0.89 \\
Q17 & $26 / 2$ & $77 / 8$ & 1.0 \\
Q18 & $26 / 2$ & $92 / 8$ & 0.25 \\
Q19 & $10 / 7$ & $69 / 8$ & 0.83 \\
Q20 & $40 / 3$ & $92 / 8$ & 0.48 \\
\hline Note: Testres & $24 / 9$ & $92 / 8$ & 0.25 \\
\hline
\end{tabular}

Note: Test-retest was performed in 12 randomly selected patients.

reliable, and valid instrument to assess HRQOL in Danish patients with strabismus.

HRQOL instruments are divided into generic and those specific to a condition. Generic measures allow comparisons between conditions but lack sensitivity in capturing

Table 4 Difference in AS-20 score between patients with diplopia and patients without diplopia

\begin{tabular}{llll}
\hline & $\begin{array}{l}\text { Nondiplopic median } \\
\text { (IQR) }\end{array}$ & $\begin{array}{l}\text { Diplopic median } \\
\text { (IQR) }\end{array}$ & P-value \\
\hline Q1 & $62.5(25-100)$ & $50.00(0-75)$ & 0.78 \\
Q2 & $75.00(50-100)$ & $25.00(25-75)$ & $0.007^{*}$ \\
Q3 & $62.5(25-75)$ & $25.00(25-75)$ & 0.69 \\
Q4 & $50.00(25-75)$ & $25.00(25-75)$ & 0.192 \\
Q5 & $25.00(0-75)$ & $0(0-25)$ & 0.241 \\
Q6 & $50.00(25-75)$ & $25.00(0-25)$ & 0.185 \\
Q7 & $50.00(25-50)$ & $0(0-50)$ & $0.036^{*}$ \\
Q8 & $25.00(25-75)$ & $0(0-50)$ & $0.012^{*}$ \\
Q9 & $25.00(0-50)$ & $0(0-50)$ & 0.051 \\
Q10 & $25.00(0-75)$ & $25.00(0-50)$ & 0.507 \\
Q11 & $50.00(0-75)$ & $50.00(50-75)$ & 0.136 \\
Q12 & $0(0-25)$ & $0(0-25)$ & 0.736 \\
Q13 & $25.00(0-25)$ & $25.00(0-50)$ & 0.462 \\
Q14 & $50.00(25-50)$ & $50.00(25-50)$ & 0.832 \\
Q15 & $50.00(50-75)$ & $50.00(25-75)$ & 0.132 \\
Q16 & $25.00(25-75)$ & $25.00(25-75)$ & 0.857 \\
Q17 & $25.00(00-50)$ & $50.00(25-50)$ & 0.161 \\
Q18 & $50.00(25-75)$ & $50.00(50-75)$ & 0.419 \\
Q19 & $25.00(0-25)$ & $25.00(0-50)$ & 0.705 \\
Q20 & $25.00(0-50)$ & $50.00(0-75)$ & 0.262 \\
\hline
\end{tabular}

Note: *Significant differences between the two groups.

Abbreviations: AS-20, Adult Strabismus Quality of Life Questionnaire; IQR, interquartile range. the specific impact of ophthalmological-related symptoms associated with strabismus and other ophthalmic disorders. Vision-specific instruments such as the Visual Function Questionnaire (VFQ-25) have been developed to better capture the impact of visual disturbances in QOL. The VFQ-25 examines the influence of visual disability and visual symptoms on generic health domains such as emotional well-being and social functioning as well as a task-orientated domain specific to daily functioning. Our group has developed the Danish translation of the VFQ-25, and it was shown to give reliable and valid results when administered to patients with age-related macular degeneration. ${ }^{13}$

The VFQ-25 however contains only few items relating to strabismus-specific issues (such as appearance or other related psychosocial concerns). The AS-20 questionnaire was developed to measure the specific concerns associated with strabismus, addressing functional factors related to diplopia and asthenopia and psychosocial factors such as psychological distress with appearance, anxiety for social acceptance, impaired communication ability due to poor eye contact, and social avoidance. The AS-20's sensitivity is greater than the VFQ-25 across the range of adult strabismus patients and has higher discriminatory ability, particularly in nondiplopic patients. ${ }^{9}$

In our patient series, the percentage of patients with incomitant strabismus was $6.25 \%$ (four patients) and with diplopia 33.8\% (22 patients).

The Danish version of the AS-20 showed good discriminative validity with significantly lower psychosocial, functional, and overall scores (thus indicating worse HRQOL) for strabismus patients with and without diplopia. The only item that scored slightly different was item 14 (problems with depth perception). Indeed, a Rasch analysis of the AS-20 has suggested removing item 14 and item 19, thus improving subscale performance. ${ }^{14}$ Differences in scoring in the subscales by the patients with and without diplopia were not significant. Our control group and strabismus groups were not age matched, which could result in different discriminatory power results had they been. However, we believe that our study does validate the discriminatory power of AS-20 despite that.

\section{Conclusion}

We found that the Danish version of AS-20 shows high reliability and validity. Danish patients with strabismus are highly affected in a negative way on self-perceived HRQOL. They report significantly lower scores compared to individuals with no eye disease and to a level (composite score 63) comparable to the Chinese patients ${ }^{12}$ with an 
average score of 63, underscoring the importance of having a valid tool, such as the AS-20, for the assessment of disability among patients with strabismus.

\section{Disclosure}

The authors report no conflicts of interest in this work.

\section{References}

1. Satterfield D, Keltner JL, Morrison TL. Psychosocial aspects of strabismus study. Arch Ophthalmol. 1993;111:1100-1105.

2. Burke JP, Leach CM, Davis H. Psychosocial implications of strabismus surgery in adults. J Pediatr Ophthalmol Strabismus. 1997;34:159-164.

3. Menon V, Saha J, Tandon R, Mehta M, Khokhar S. Study of the psychosocial aspects of strabismus. J Pediatr Ophthalmol Strabismus. 2002;39: 203-208.

4. Jackson S, Harrad RA, Morris M, Rumsey N. The psychosocial benefits of corrective surgery for adults with strabismus. Br J Ophthalmol. 2006; 90:883-888.

5. Coats DK, Paysse EA, Towler AJ, Dipboye RL. Impact of large angle horizontal strabismus on ability to obtain employment. Ophthalmology. 2000;107:402-405.

6. Olitsky SE, Sudesh S, Graziano A, Hamblen J, Brooks SE, Shaha SH. The negative psychosocial impact of strabismus in adults. J AAPOS. 1999;3:209-211.
7. Hatt SR, Leske DA, Kirgis PA, Bradley EA, Holmes JM. The effects of strabismus on quality of life in adults. Am J Ophthalmol. 2007;144: 643-647.

8. Hatt SR, Leske DA, Bradley EA, Cole SR, Holmes JM. Development of a quality-of-life questionnaire for adults with strabismus. Ophthalmology. 2009;116(1):139-144.

9. Hatt SR, Leske DA, Holmes JM. Responsiveness of health-related quality of life questionnaires in adults undergoing strabismus surgery. Ophthalmology. 2010;117:2322-2328.

10. Hatt SR, Leske DA, Liebermann L, Holmes JM. Changes in health related quality of life 1 year following strabismus surgery. $\mathrm{Am} \mathrm{J}$ Ophthalmol. 2012;153:614-619.

11. Liebermann L, Hatt SR, Leske DA, Holmes JM. Improvement in specific function-related quality-of-life concerns after strabismus surgery in nondiplopic adults. $J$ AAPOS. 2014;18:105-109.

12. Yu H, Yang X, Ye T, Chen J, Zhang F, Yu X. Development and evaluation of a chinese version of the adult strabismus questionnaire (AS-20). Ophthalmic Epidemiol. 2013;20(4):239-247.

13. Sørensen MS, Andersen S, Henningsen G, Larsen CT, Sørensen TL. Danish version of Visual Function Questionnaire-25 and its use in age-related macular degeneration. Dan Med Bul. 2011;58(6):A4290.

14. Leske DA, Hatt SR, Liebermann L, Holmes JM. Evaluation of the adult strabismus-20 (AS-20) questionnaire using Rasch analysis. Invest Ophthalmol Vis Sci. 2012;53:2630-2639.
Clinical Ophthalmology

\section{Publish your work in this journal}

Clinical Ophthalmology is an international, peer-reviewed journal covering all subspecialties within ophthalmology. Key topics include: Optometry; Visual science; Pharmacology and drug therapy in eye diseases; Basic Sciences; Primary and Secondary eye care; Patient Safety and Quality of Care Improvements. This journal is indexed on

Submit your manuscript here: http://www.dovepress.com/clinical-ophthalmology-journal

\section{Dovepress}

PubMed Central and CAS, and is the official journal of The Society of Clinical Ophthalmology (SCO). The manuscript management system is completely online and includes a very quick and fair peer-review system, which is all easy to use. Visit http://www.dovepress.com/ testimonials.php to read real quotes from published authors. 